\title{
ASSOCIAÇÃO ENTRE A DETECÇÃO DE DEFEITOS ÓSSEOS PERIAPICAIS EM RADIOGRAFIAS BIDIMENSIONAIS E A CLASSIFICAÇÃO DO ÍNDICE PERIAPICAL UTILIZADO EM IMAGENS DE TCFC
}

\section{Lais O.A. Cardelli, Eduarda H.L. Nascimento, Rocharles C. Fontenele, Hugo Gaêta-Araujo, Deborah Q. Freitas.}

\section{Resumo}

O objetivo neste trabalho foi avaliar a taxa de detecção de defeitos ósseos periapicais em radiografias panorâmicas (PAN) e periapicais (PERI) considerando os fatores avaliados na classificação do índice periapical em imagens de TCFC. Foram avaliados exames de pacientes atendidos na Clínica de Radiologia da FOP/UNICAMP, os quais foram divididos em dois grupos: PAN+TCFC e PERI+TCFC. As radiografias foram avaliadas por dois examinadores quanto à presença de radiolucências apicais. As imagens de TCFC foram avaliadas quanto ao tamanho das radiolucências, a presença e o grau de afinamento cortical, localização do dente afetado e morfologia radicular. A taxa de detecção variou entre $22,6 \%$ (PERI) e 27,4\% (PAN). A PERI apresentou valores de diagnóstico mais elevados que a PAN. O tamanho das radiolucências foi positivamente correlacionado com sua detecção na PERI e na PAN $(p<0,001)$. Em conclusão, o tamanho da radiolucência apical é o fator que mais contribui para sua detecção radiográfica.

Palavras-chave: radiografia, tomografia computadorizada de feixe cônico, diagnóstico, endodontia.

\section{Introdução}

As periapicopatias resultam em reabsorções ósseas identificadas radiograficamente como radiolucências. Radiografias, como a periapical e a panorâmica, são usadas rotineiramente, mas tais radiolucências podem não ser vistas em exames bidimensionais devido à sobreposição de imagem inerente à técnica radiográfica. Um dos métodos utilizados para avaliação radiográfica das periapicopatias é o índice periapical (IP). No entanto, devido às limitações das radiografias e ao uso crescente de imagens tridimensionais na Odontologia, estudos introduziram um novo IP baseado em imagens de TCFC. ${ }^{1,2}$ O principal objetivo desse estudo foi avaliar a taxa de detecção de defeitos ósseos periapicais em imagens bidimensionais (radiografia panorâmica e radiografia periapical) considerando fatores avaliados na classificação do IP em imagens de TCFC.

\section{Resultados e Discussão}

\begin{tabular}{|c|c|}
\hline Grupo 1 & Grupo 2 \\
\hline PERI + TCFC & PAN + TCFC \\
\hline 94 dentes (115 raizes) & 227 dentes (285 raizes) \\
\hline
\end{tabular}

- Radiografias: presença x ausência de radiolucências apicais;

- TCFC (padrão de referência): tamanho das radiolucências, presença e o grau de afinamento cortical, localização do dente (anterior/posterior de maxila/mandíbula) e morfologia radicular.

Tabela 1. Detecção das radiolucências apicais nas radiografias periapical e panorâmica comparada com a TCFC

\begin{tabular}{|c|c|c|c|c|c|}
\hline & \multicolumn{3}{|c|}{ TCFC } & \multirow{2}{*}{$\begin{array}{c}\text { P. } \\
\text { valor* }\end{array}$} \\
\hline & & Ausência & Presença & Total & \\
\hline $\begin{array}{l}\text { Radiografia } \\
\text { Periapical }\end{array}$ & $\begin{array}{l}\text { Ausência } \\
\text { Presença } \\
\text { Total }\end{array}$ & $\begin{array}{c}79 \\
10 \\
89(77.4)\end{array}$ & $\begin{array}{c}9 \\
17 \\
26(22.6)\end{array}$ & $\begin{array}{l}88(76.5) \\
27(23.5) \\
115(100)\end{array}$ & $<0.001$ \\
\hline $\begin{array}{l}\text { Radiografia } \\
\text { Panorâmica }\end{array}$ & $\begin{array}{l}\text { Ausência } \\
\text { Presença } \\
\text { Total }\end{array}$ & $\begin{array}{c}189 \\
18 \\
207(72.6) \\
\end{array}$ & $\begin{array}{c}47 \\
31 \\
78(27.4) \\
\end{array}$ & $\begin{array}{c}236(82.8) \\
49(17.2) \\
285(100)\end{array}$ & $<0.001$ \\
\hline
\end{tabular}
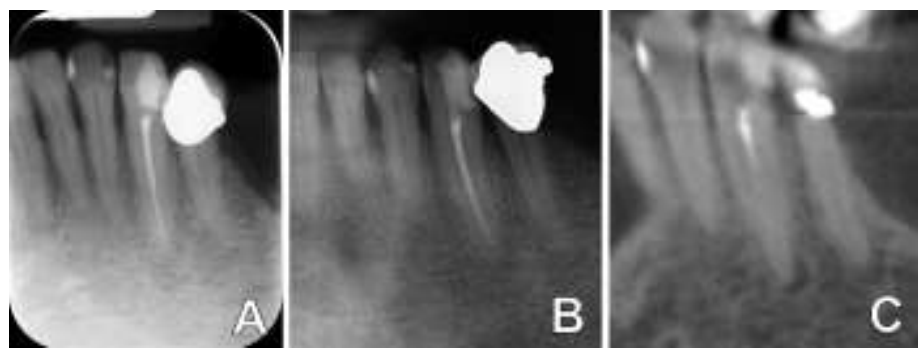

Figura 1. Radiolucência apical no dente 33. (A) Radiografia periapical; (B) radiografia panorâmica; $(C)$ imagem de TCFC.

Table 3. Testes de diagnóstico relacionados às radiografias periapical (PERI) e panorâmica (PAN)

\begin{tabular}{lccccc} 
& Acurácia & Sensibilidade & Especificidade & VPP & VPN \\
\hline PERI & 0.83 & 0.65 & 0.89 & 0.63 & 0.90 \\
PAN & 0.77 & 0.40 & 0.91 & 0.63 & 0.80
\end{tabular}

VPP, valores preditivos positivos; VPN, valores preditivos negativos

\section{- Correlação de Spearmann:}

- Correlação positiva e significativa entre o tamanho da radiolucência e sua taxa de detecção para PERI $(R=0,565$, moderada, $p<0,001)$ e PAN $(R=0,232$, leve, $\mathrm{p}<0,001)$.

\section{- Regressão logística:}

- O tamanho da radiolucência foi significativamente relacionado à sua detecção, tanto na PERI quanto na PAN $(p<0,05)$.

- Na PERI, as radiolucências apicais foram mais frequentemente detectadas quando estavam relacionadas a dentes unirradiculares $(p=0.037)$.

\section{Conclusões}

O tamanho das radiolucências apicais é o fator que mais contribui para a detecção radiográfica das periapicopatias.

\footnotetext{
${ }^{1}$ Estrela, C.; Bueno, M.R.; Azevedo, B.C.; Azevedo, J.R e Pécora, D.P. J. Endod. 2008, 34, 1325-1331.
}

${ }^{2}$ Esposito, S.; Cardaropoli, M. e Cotti, E. J. Endod. 2011, 40, 506-512.

According to Pearson's chi-squared test 